\title{
Simulation of the process kinetics and analysis of physicochemical properties in the freeze drying of kale
}

\author{
Dariusz Dziki ${ }^{1}$, Renata Polak ${ }^{1}$, Stanisław Rudy ${ }^{1}$, Andrzej Krzykowski ${ }^{1}$, Urszula Gawlik-Dziki ${ }^{2}$, \\ Renata Różyło ${ }^{3}$, Antoni Miśs ${ }^{4}$ and Maciej Combrzyński ${ }^{1}$ \\ ${ }^{1}$ Department of Thermal Technology and Food Process Engineering, University of Life Sciences, Doświadczalna 44, 20-280 Lublin, \\ Poland \\ ${ }^{2}$ Department of Biochemistry and Food Chemistry, University of Life Sciences, Skromna 8, 20-704 Lublin, Poland \\ ${ }^{3}$ Department of Equipment Operation and Maintenance in the Food Industry, University of Life Sciences, Doświadczalna 44, \\ 20-280 Lublin, Poland \\ ${ }^{4}$ Institute of Agrophysics, Polish Academy of Sciences, Doświadczalna 4, 20-290 Lublin, Poland
}

Received February 28, 2017; accepted October 27, 2017

\begin{abstract}
A b stract. Investigations were performed to study the freezedrying process of kale (Brassica oleracea L. var acephala). The process of freeze-drying was performed at temperatures of 20, 40, and $60^{\circ} \mathrm{C}$ for whole pieces of leaves and for pulped leaves. The kinetics of the freeze-drying of both kale leaves and kale pulp were best described by the Page model. The increasing freezedrying temperature from 20 to $60^{\circ} \mathrm{C}$ induced an approximately two-fold decrease in the drying time. Freeze-drying significantly increased the value of the lightness, delta Chroma, and browning index of kale, and had little influence on the hue angle. The highest increase in the lightness and delta Chroma was observed for whole leaves freeze-dried at $20^{\circ} \mathrm{C}$. An increase in the drying temperature brought about a slight decrease in the lightness, delta Chroma and the total colour difference. Pulping decreased the lightness and hue angle, and increased browning index. Freeze-drying engendered a slight decrease in the total phenolics content and antioxidant activity, in comparison to fresh leaves. The temperature of the process and pulping had little influence on the total phenolics content and antioxidant activity of dried kale, but significantly decreased the contents of chlorophyll $a$ and chlorophyll $b$.

Keyw ords: kale, freeze-drying, temperature, colour, antioxidant activity
\end{abstract}

\section{INTRODUCTION}

Greater vegetable consumption is increasingly being recommended as part of a healthy lifestyle. Several studies have shown that a diet rich in fruits and vegetables decreases the risk of developing the inflammation and oxidative stresses that are indicative of many diseases (Murador et al., 2016). In particular, epidemiological studies have shown an

*Corresponding author e-mail: dariusz.dziki@up.lublin.pl inverse relationship between the consumption of Brassica vegetables and the development of cancer and cardiovascular diseases (Steindal et al., 2014). Such anticancer attributes have been linked to the contained glucosinolates and their degradation products, in addition to other compounds (Traka and Mithen, 2008; Verkerk et al., 2009).

Curly kale (Brassica oleracea L. var Acephala) is a biannual leafy vegetable, a member of the cabbage family, and widely grown in all the East African countries and in many other parts of the world, including Europe, Asia and Latin America (Mwithiga and Olwal, 2005). Kale plants are robust and can tolerate cold temperatures, even $-18^{\circ} \mathrm{C}$ (Steindal et al., 2014). Its foliage is rich in nutrients and bioactive compounds such as vitamins, minerals, glucosinolates and phenolic compounds (Ayaz et al., 2006; Armesto et al., 2015). However, the foliage has a high moisture content (approximately 86\% w.b.) at harvest and, therefore, it cannot be preserved for more than a few days under ambient conditions of $20-25^{\circ} \mathrm{C}$ (Korus, 2011; Mwithiga and Olwal, 2005).

Leaf senescence involves the loss of chlorophyll and other constituents, membrane deterioration and nutrient recycling (Guiboileau et al., 2010). These changes are largely temperature-controlled in the harvested products (Albornoz and Cantwell, 2016). Furthermore, the high presence of naturally occurring microorganisms on fresh vegetables may lead to the rejection of the product by consumers because of spoilage, even though these are

(C) 2018 Institute of Agrophysics, Polish Academy of Sciences 
usually nonpathogenic for humans. Moreover, the damage of the fresh vegetable surfaces during peeling, cutting, and shredding may worsen the contamination with spoilage microorganisms (Mansur and Oh, 2015). Consequently, it may reduce the microbial and sensory shelf life of the end-product (Ragaert et al., 2007). Therefore, we need to develop an effective preservation method that can enhance the shelf life of fresh-cut kale during storage.

To overcome this limitation, drying processes can be used as methods to increase the shelf life of this easily perishable food product. Drying is a mass transfer process consisting of the removal of water by evaporation from the material so as to increase the shelf life of vegetables. This process is important and often used as a final production step before selling or packaging products (Huang et al., 2015). Vegetables are important source of phytochemicals known to provide health benefits (Van Duyn and Pivonka, 2000), but these compounds generally undergo significant degradation during drying because of their sensitivity to heat, oxygen and light (Oliveira et al., 2015).

Convective drying is one of the most important drying techniques used to dry vegetables. However, it often causes a high degradation of naturally heat-sensitive substances, such as antioxidants, vitamins, minerals, pigments, and other bioactive compounds (Araújo et al., 2017). Oliveira et al. (2015) found that the antioxidant capacity losses from 52 to $70 \%$ with an increase in the air drying temperature increases from 35 to $85^{\circ} \mathrm{C}$. They also found a degradation of chlorophyll a from 9 to $35 \%$, and that of vitamin C, from 566.1 to $252.1 \mathrm{mg} 100 \mathrm{~g}^{-1}$ dry mass. Thus, increased attention should be given to the concerns regarding the quality degradation of kale during drying.

Freeze-drying, or 'lyophilization', has long been known as the best drying method for preserving the original properties of the raw material. This process is known to extend the shelf-life of foods by preventing microbial growth and retarding lipid oxidation (Nakagawa et al., 2015). Freeze drying, in particular, preserves a higher level of bioactive compounds than does air-drying (Sogi et al., 2013). Hence, this process is generally recommended for drying materials containing heat-sensitive components such as tocopherols, ascorbic acid, carotenoids, and plant phenolics (Shofian et al. 2011).

A few studies have been conducted regarding the freezedrying of kale. Korus (2011) showed that freeze-dried kale leaves contained higher levels of antioxidants than did airdried material: polyphenols, vitamin $\mathrm{C}$, and antioxidant activity expressed as trolox equivalent were, respectively, 36,15 , and 33\% higher. Moreover, Korus $(2012,2013)$ also pointed out that the levels of chlorophylls, carotenoids and individual amino acids content were higher in freezedried than in air-dried products, and from a practical point of view, she concluded that blanching was not a necessary procedure before drying kale leaves. Still, there is virtually no data in the literature on the freeze-drying kinetics of whole and pulped kale leaves or the extent to which the temperature of this process impacts on the physicochemical properties of dried kale.

The aim of the present work was to study the influence of the freeze-drying temperature and the pulping on the drying characteristics and quality parameters of kale leaves.

\section{MATERIAL AND METHODS}

The material investigated consisted of raw kale leaves (Brassica oleracea L. var acephala) cv. Lerchenzungen. Fresh kale leaves (moisture content $866 \mathrm{~g} \mathrm{~kg}^{-1}$ fresh weight) were harvested during the last five days of September from the University of Life Sciences in Lublin in 2015 and immediately used for the experiments. For the investigations, leaves without discoloration and damage were taken. The process of drying was preceded by a preliminary treatment of the leaves: removal of the main vein and washing. Two types of leaf samples were dried: whole pieces (WL) of leaves (about $5 \mathrm{~cm}$ long and $1 \mathrm{~cm}$ wide) and leaves after pulping (PL) into a homogeneous mass (30 s) by using a knife grinder (Braun, Model 2001, Germany) with a speed of 8.000 r.p.m.

Samples of the raw material were frozen at $-35^{\circ} \mathrm{C}$ for $48 \mathrm{~h}$ by using a freezer (Panasonic, MDF-U5412-PE, Japan), and freeze-dried (a single layer of whole leaves and about $0.5 \mathrm{~mm}$ of pulping leaves). Frozen samples were immediately transferred to a freeze-drier. The same mass of sample $(0.3 \mathrm{~kg})$ was freeze-dried each time by using an ALPHA 1-4 laboratory freeze dryer consisting of drying chamber, a cold trap, a vacuum pump, and a measurement and control system. The freeze-dryer was also equipped with a trap heating system linked to and co-operated with an LDC-1M driver (Martin Christ Company) and integrated with a weight system equipped with an electronic balance for measuring the mass changes of the samples during drying (Rudy et al., 2015). The mass of the material was recorded continuously during the drying process (to an accuracy of $\pm 0.1 \mathrm{~g}$ ). The drying process was continued at 20,40 and $60^{\circ} \mathrm{C}$ and with a constant pressure in the drying chamber of $52 \mathrm{~Pa}$ until the sample mass reached the equilibrium water content $\left(u_{r}\right)$ of approximately $40 \mathrm{~g} \mathrm{H}_{2} \mathrm{O} /$ $\mathrm{kg} \mathrm{FW}$. The process at a decreased pressure in the freezedrying chamber took approximately $120 \mathrm{~s}$, and the cool traps were heated continuously to the set temperature level. The temperature of the traps was increased at the beginning of drying and reached an adequate level from 10 to $20 \mathrm{~min}$.

Relying on the measurements of the mass loss taken during the experiment, drying curves were charted as functions of the moisture ratio $(M R)$ versus time, using the following equation:

$$
M R=\frac{u-u_{r}}{u_{0}-u_{r}},
$$


where: $u$ denotes the water content in the course of drying $\left(\mathrm{kg} \mathrm{H}_{2} \mathrm{O} \mathrm{kg}^{-1} \mathrm{DM}\right)$ and $u_{0}$ represents the initial water content $\left(\mathrm{kg} \mathrm{H}_{2} \mathrm{O} \mathrm{kg}{ }^{-1} \mathrm{DM}\right)$. The seven semi-theoretical and empirical models were used to describe the drying kinetics of kale (Table 1).

The colour values $\left(L^{*}, a^{*}\right.$ and $\left.b^{*}\right)$ of fresh and dried kale were assessed using a Minolta CR-400 colorimeter (Konica-Minolta, Osaka, Japan), calibrated with a white standard tile. The analyses of the colour values were performed five times with each dried kale sample. From the data obtained, the values of delta Chroma $(\Delta C)$, hue angle $(H U)$, total colour difference $(T D C)$ and browning index $(B I)$ were calculated according to the following equations (Alibas, 2009):

$$
\begin{gathered}
\Delta C=\sqrt{\left(a^{*}\right)+\left(b^{*}\right)^{2}}, \\
H U=\tan ^{-1} \frac{b}{a}, \\
T D C=\sqrt{\left(L_{0}-L\right)^{2}+\left(a_{0}-a\right)^{2}+\left(b_{0}-b\right)^{2}},
\end{gathered}
$$

where: the index ' 0 ' indicated the fresh unpulped leaves:

in which:

$$
B I=\frac{100(x-0.31)}{0.17},
$$

$$
x=\frac{a^{*}+1.75 L^{*}}{5.645 L^{*}+a^{*}-3.012 b^{*}} .
$$

Quantitative chlorophyll determinations for fresh and dried kale samples were performed by reading absorbance at $665.2\left(A_{1}\right)$ and $652.4\left(A_{2}\right) \mathrm{nm}$ in a spectrophotometer (Diode Array, Hewlett-Packard 8453, Waldbronn, Germany) according to the procedure described by Lichtenthaler (Oliveira et al., 2015). The total chlorophyll was calculated as the sum of chlorophyll $a\left(C_{a}\right)$ and chlorophyll $b\left(C_{b}\right)$ :

$$
\begin{aligned}
& C_{a}=16.72 A_{1}-9.16 A_{2}, \\
& C_{b}=34.09 A_{2}-15.28 A_{1} .
\end{aligned}
$$

The chlorophyll contents were expressed in milligrammes per gramme of dry mass (DM).

For extract preparation, the ordered samples of kale $(1 \mathrm{~g} \mathrm{DM})$ were extracted for $30 \mathrm{~min}$ with $20 \mathrm{ml}$ of a methanol:water solution $(1: 1, \mathrm{v} / \mathrm{v}), \mathrm{pH}=1$. The extracts were separated by decantation and the residues were extracted again with $20 \mathrm{ml}$ of this solvent. Extracts were combined and stored in darkness at $-20^{\circ} \mathrm{C}$. Total phenolics were estimated according to the Folin-Ciocalteau method (Singleton and Rossi, 1965). A $0.5 \mathrm{ml}$ sample of the extract was mixed with $0.5 \mathrm{ml}$ of $\mathrm{H}_{2} \mathrm{O}, 2 \mathrm{ml}$ of the Folin reagent $\left(1: 5 \mathrm{H}_{2} \mathrm{O}\right)$, and after $3 \mathrm{~min}$, with $10 \mathrm{ml}$ of $10 \mathrm{~g} 100 \mathrm{ml}^{-1} \mathrm{Na}_{2} \mathrm{CO}_{3}$. After $30 \mathrm{~min}$, the absorbance of the mixed samples was measured at a wavelength of $720 \mathrm{~nm}$. The amount of total phenolics (corrected for the added ascorbic acid content) was expressed as a gallic acid equivalent (GAE) per $g$ of dry mass.

The antioxidant activity (AA) was performed using an improved ABTS (2,20-azino-bis (3-ethylbenzothiazoline-6-sulphonic acid)) decolorization assay (Re et al., 1999). The ability of the extracts to quench the ABTS free radicals was determined using the following equation:

$$
A A=\frac{A_{C}-A_{A}}{A_{C}} 100 \%,
$$

\begin{tabular}{|c|c|c|c|}
\hline \multirow[b]{2}{*}{ Number } & \multirow[b]{2}{*}{ Name } & Model & \multirow{2}{*}{ References } \\
\hline & & Equation & \\
\hline 1 & Newton & $M R=\exp (-k \tau)$ & Demir et al. (2004) \\
\hline 2 & Page & $M R=\exp \left(-k \tau^{\mathrm{n}}\right)$ & Sarimeseli (2011) \\
\hline 3 & Henderson and Pabis & $M R=a \exp (-k \tau)$ & Henderson and Pabis (1961) \\
\hline 4 & Logarithmic & $M R=a \exp (-k \tau)+b$ & Sarimeseli (2011) \\
\hline 5 & Wang and Singh & $M R=1+a \tau+b \tau^{2}$ & Wang and Singh (1978) \\
\hline 6 & Logistic & $M R=b\left((1+a \exp (-k \tau))^{-1}\right.$ & Soysal et al (2006) \\
\hline 7 & Two-factor & $M R=a \exp (-k \tau)+b \exp \left(-k_{i} \tau\right)$ & Arslan and Özcan (2008) \\
\hline
\end{tabular}

where: $A_{C}$ denotes the absorbance of the control and $A_{A}$ represents the absorbance of the sample.

The antiradical activity was expressed as $\mathrm{EC}_{50}$ - the extract concentration provided. Accordingly, there was $50 \%$ activity based on the dose-dependent mode of action.

Table 1. Equations applied to drying curves

$k, k_{i}$-drying coefficients $\left(\mathrm{min}^{-1}\right) ; a, b$ - coefficients of the equations; $n$ - exponent; $\tau$ - time (min). 
All tests were performed in triplicate. The measurement scores were expressed as means \pm standard deviation. The measurement scores were subjected to a two-factor analysis of variance (ANOVA). When significant differences in ANOVA were detected, the means were compared using the Tukey test. Statistical analysis was performed at a significance level of $\alpha=0.05$, by using the Statistica software (StatSoft, version 6.0). A regression analysis was also performed. The coefficient of determination $\mathrm{R}^{2}$, root mean square error (RMSE), and the reduced $\chi^{2}$ values were calculated as follows:

$$
\begin{gathered}
R M S E=\sqrt{\frac{\sum_{i=1}^{N}\left(M R_{i, p}-M R_{i, e}\right)^{2}}{N}}, \\
\chi^{2}=\frac{\sum_{i=1}^{N}\left(M R_{i, p}-M R_{i, e}\right)^{2}}{N-n},
\end{gathered}
$$

where: $M R_{i, p}$ denotes the model-based value of the water ratio, $M R_{i, e}$ represents the experimentally obtained value of the water ratio, $N$ indicates the number of observations, and $n$ stands for the number of constant parameters in the equation. Next, these parameters were served as a basis for the evaluation of suitability of the considered models. In general, the higher the $\mathrm{R}^{2}$ values and the lower the $\chi^{2}$ and $R M S E$ values indicate that the model is best fitted.

\section{RESULTS AND DISCUSSION}

Drying curves as functions of the water content versus time are presented in Figs 1 and 2. Both the freeze-drying temperature and the pulping significantly increased the drying rate. The freeze-drying time for kale drying at $60^{\circ} \mathrm{C}$ was about three times and two times shorter for WL and PL lyophilized at $20^{\circ} \mathrm{C}$, respectively. Pulping also decreased the drying time. However, the effect was of the most visibility for kale freeze-dried at the lowest temperature $\left(20^{\circ} \mathrm{C}\right.$; decrease in the drying time of about $\left.36 \%\right)$. Rudy et al. (2015) also pointed out that the pulping of cranberries before freeze-drying also reduced the drying time by approximately two-fold.

The results of the regression analyses for the seven considered models used to describe the freeze drying kinetics of the WL and PL are presented in Table 2. Note that, for six of the models, a good fit for the experimental data was observed. Only for the Wang and Singh model were relative lower values of $\mathrm{R}^{2}$ and $R M S E$ obtained. All the calculated $\mathrm{R}^{2}$ values fell in the 0.836-0.999 range, whereas the RMSE changed from 0.0069 to 0.0980 . Both for WL and PL, the highest values of $\mathrm{R}^{2}$ and the lowest values of RMSE were obtained when the Page model was used to describe the drying kinetics of kale. The drying curve presented in Figs 1 and 2 show a comparison of the experimental data and the predicted data based on the Page model. The calculated coefficients for the relevant equations are listed in Table 3. Similarly, Marques and Freire (2005) and Kirmaci et al.


Fig. 1. Drying curves of freeze-dried kale with experimental and predicted data based on the Page model; A - whole leaves, B pulped leaves, and $M R$ - moisture ratio.

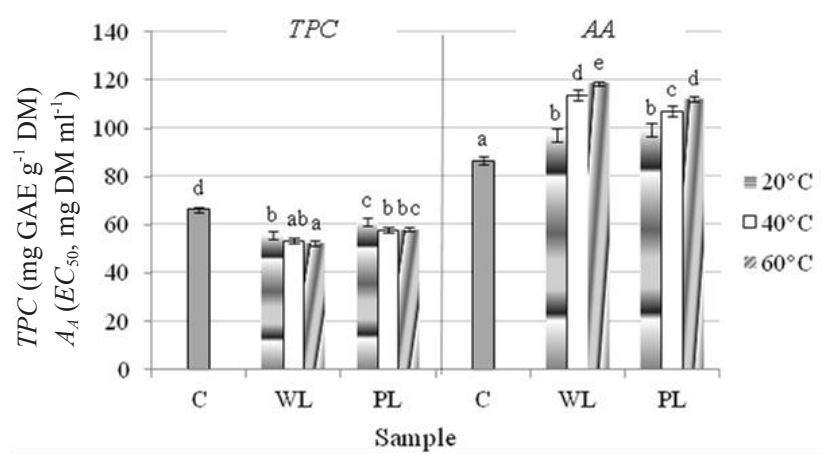

Fig. 2. Total phenolics content $(T P C)$ and antioxidant activity $(A A)$ of kale before and after freeze-drying; $\mathrm{C}$ - fresh leaves, WL - whole dried leaves, and PL - pulped dried leaves; values designated by the different letters are statistically significantly different $(\alpha=0.05)$.

(2008) found that the best equation to represent the drying kinetics for the freeze-drying of pineapple, guava, mango pulps and strawberries was that of the Page model.

During the thermal processing of plant materials, the structural characteristics of natural plant pigments are often modified and the colour of the products usually changes. Colour has to be considered as a special parameter that seems to be one of the first attributes of quality that a consumer perceives (Darvishi et al., 2014). The average 
Table 2. Statistical analysis of models describing the kinetics of freeze-drying of whole and pulped kale leaves

\begin{tabular}{|c|c|c|c|c|c|c|c|c|c|}
\hline \multirow{3}{*}{ Model name } & \multicolumn{9}{|c|}{ Drying temperature $\left({ }^{\circ} \mathrm{C}\right)$} \\
\hline & \multicolumn{3}{|c|}{20} & \multicolumn{3}{|c|}{40} & \multicolumn{3}{|c|}{60} \\
\hline & $\mathrm{R}^{2}$ & $R M S E$ & $\chi^{2}$ & $\mathrm{R}^{2}$ & $R M S E$ & $\chi^{2}$ & $\mathrm{R}^{2}$ & $R M S E$ & $\chi^{2}$ \\
\hline \multicolumn{10}{|c|}{ Whole kale leaves } \\
\hline Newton & 0.999 & 0.0077 & 0.00006 & 0.992 & 0.024 & 0.0006 & 0.982 & 0.0394 & 0.0016 \\
\hline Page & 0.999 & 0.0069 & 0.00005 & 0.998 & 0.011 & 0.0001 & 0.999 & 0.0094 & 0.00009 \\
\hline Henderson and Pabis & 0.999 & 0.0077 & 0.00006 & 0.994 & 0.021 & 0.0005 & 0.987 & 0.0328 & 0.0011 \\
\hline Logarithmic & 0.999 & 0.0074 & 0.00006 & 0.994 & 0.0189 & 0.0004 & 0.991 & 0.0268 & 0.0008 \\
\hline Wang and Singh & 0.836 & 0.0980 & 0.00980 & 0.915 & 0.0772 & 0.0061 & 0.969 & 0.0514 & 0.0028 \\
\hline Logistic & 0.999 & 0.0077 & 0.00006 & 0.994 & 0.021 & 0.0005 & 0.987 & 0.0328 & 0.0012 \\
\hline Two-factor & 0.999 & 0.0077 & 0.00006 & 0.992 & 0.024 & 0.0006 & 0.982 & 0.0394 & 0.0016 \\
\hline \multicolumn{10}{|c|}{ Pulped kale leaves } \\
\hline Newton & 0.994 & 0.0216 & 0.0005 & 0.985 & 0.0342 & 0.0012 & 0.979 & 0.0447 & 0.0021 \\
\hline Page & 0.994 & 0.0081 & 0.00007 & 0.999 & 0.007 & 0.00005 & 0.9999 & 0.0032 & 0.00001 \\
\hline Henderson and Pabis & 0.994 & 0.0175 & 0.0003 & 0.992 & 0.0251 & 0.0007 & 0.987 & 0.0347 & 0.0013 \\
\hline Logarithmic & 0.990 & 0.0109 & 0.0001 & 0.993 & 0.0233 & 0.0006 & 0.993 & 0.0249 & 0.0007 \\
\hline Wang and Singh & 0.945 & 0.0637 & 0.0042 & 0.923 & 0.0771 & 0.0062 & 0.990 & 0.0306 & 0.0010 \\
\hline Logistic & 0.996 & 0.0175 & 0.0003 & 0.992 & 0.0251 & 0.0007 & 0.987 & 0.0347 & 0.0013 \\
\hline Two-factor & 0.993 & 0.0087 & 0.0002 & 0.992 & 0.024 & 0.0006 & 0.982 & 0.0394 & 0.0016 \\
\hline
\end{tabular}

Table 3. Coefficient values in the models describing the freeze drying of whole (WL) and pulped (PL) kale leaves - Page model

\begin{tabular}{cccc}
\hline $\begin{array}{c}\text { Drying } \\
\text { temperature } \\
\left({ }^{\circ} \mathrm{C}\right)\end{array}$ & Sample & $k\left(\mathrm{~min}^{-1}\right)$ & $\mathrm{n}$ \\
\hline 20 & $\mathrm{WL}$ & 0.0036 & 1.1806 \\
40 & & 0.0025 & 1.3314 \\
60 & & 0.0035 & 1.1586 \\
20 & $\mathrm{PL}$ & 0.0024 & 1.3076 \\
40 & & 0.0026 & 1.3509 \\
60 & & 0.0278 \\
\hline
\end{tabular}

values for the colour parameters of fresh kale leaves were as follows: $L^{*}=37.7, D C=17.1, H U=112.3$ and $B I=$ 43.3. Pulping induced a significant decrease in lightness (up to 29.6), and slightly decreased the hue angle (up to 107.7), and increased $B I$ up to 60.41. The freeze-drying of kale significantly increased lightness, $\Delta C$ and $B I$, and had negligible impact on $H U$. The highest increase in $L^{*}$ and
$\Delta \mathrm{C}$ was observed for WL (average from 37.7 to 61.9 , and from 17.1 to 39.58 , respectively) freeze-dried at $20^{\circ} \mathrm{C}$. An increase in the drying temperature brought about a slight decrease in $L^{*}, \triangle \mathrm{C}$, and $T D C$. This tendency was observed for both PL and WL (Table 4). Araújo et al. (2016) studied the colour changes of air dried kale and found that the $L^{*}$ value slightly increased after convective drying (from 35.6 for fresh leaves to 41.3), but significantly decreased, even up to 20.8, when different methods of pretreatment, such as blanching, steaming or submerging in different solvents were used. In our study, during the freeze-drying of both WL and PL, an increase in $L^{*}$ and $B I$ was observed. $B I$ ranged from 43.3 for fresh unpulped kale leaves, to 66.8 for PL freeze-dried at $20^{\circ} \mathrm{C}$. The lowest changes in $B I$ were found for WL samples freeze-dried at $60^{\circ} \mathrm{C}$ (average 51.9). BI corresponds to a quantification of the brown colour resulting from thermal processing, and increases of this parameter reflects the development of the brown colour in kale during the drying process, as a result of the pigments formed by the effect of the enzymatic and non-enzymatic reactions (Serratosa et al., 2011). Araújo et al. (2016) found that $B I$ increased from 200 to $300 \%$ after air drying. In our study, freeze-drying only increased of $B I$ from 20 to $55 \%$. 
Table 4. Colour parameters of fresh and dried kale at different drying temperatures

\begin{tabular}{|c|c|c|c|c|c|c|}
\hline \multirow{2}{*}{ Sample } & \multirow{2}{*}{$\begin{array}{c}\text { Drying } \\
\text { temperature }\left({ }^{\circ} \mathrm{C}\right)\end{array}$} & \multicolumn{5}{|c|}{ Colour parameter } \\
\hline & & $L^{*}$ & $\Delta C$ & $H U$ & $T D C$ & $B I$ \\
\hline $\mathrm{C}$ & - & $37.70 \pm 1.79 b$ & $17.11 \pm 2.12 \mathrm{a}$ & $112.33 \pm 0.88 \mathrm{c}$ & - & $43.30 \pm 0.51 \mathrm{a}$ \\
\hline CPK & - & $29.61 \pm 0.42 \mathrm{a}$ & $18.30 \pm 0.34 \mathrm{a}$ & $107.70 \pm 0.79 \mathrm{a}$ & $5.97 \pm 0.21$ & $60.41 \pm 0.92 \mathrm{c}$ \\
\hline WL & 20 & $62.37 \pm 0.35 f$ & $39.58 \pm 0.31 \mathrm{f}$ & $112.41 \pm 0.35 \mathrm{c}$ & $32.49 \pm 0.63$ & $66.71 \pm 0.85 f$ \\
\hline PL & 20 & $56.91 \pm 0.19 \mathrm{de}$ & $37.77 \pm 0.41 \mathrm{e}$ & $111.52 \pm 0.41 \mathrm{c}$ & $27.28 \pm 0.54$ & $66.83 \pm 0.68 f$ \\
\hline WL & 40 & $61.52 \pm 0.52 \mathrm{f}$ & $36.59 \pm 0.45 \mathrm{~d}$ & $112.39 \pm 0.30 \mathrm{c}$ & $29.51 \pm 0.38$ & $62.58 \pm 0.48 \mathrm{~d}$ \\
\hline PL & 40 & $56.27 \pm 0.22 \mathrm{~d}$ & $35.92 \pm 0.26 \mathrm{~d}$ & $110.63 \pm 0.28 b$ & $25.82 \pm 0.25$ & $63.66 \pm 0.87 d$ \\
\hline WL & 60 & $57.09 \pm 0.51 \mathrm{e}$ & $34.55 \pm 0.3 \mathrm{c}$ & $109.85 \pm 0.34 \mathrm{~b}$ & $23.32 \pm 0.31$ & $51.87 \pm 0.35 \mathrm{~b}$ \\
\hline PL & 60 & $52.56 \pm 0.33 c$ & $31.56 \pm 0.41 b$ & $108.04 \pm 0.33 \mathrm{a}$ & $21.90 \pm 0.23$ & $64.10 \pm 0.60 \mathrm{e}$ \\
\hline
\end{tabular}

$\mathrm{C}$ - control sample (fresh leaves), $\mathrm{CPK}$ - fresh pulped kale, WL - whole dried leaves, PL - pulped dried leaves, $L^{*}-$ lightness, $\Delta C-$ delta chroma, $H U$ - hue angle, $T D C$ - total colour difference, $B I$ - browning index. The values designated by the different letters in the columns of the table are significantly different $(\alpha=0.05)$.

Table 5. Chlorophyll $a$ and chlorophyll $b$ content $\left(\mathrm{mg} \mathrm{g}^{-1} \mathrm{DM}\right)$ depending on temperature of the heating plates and the pretreatment of the raw material

\begin{tabular}{|c|c|c|c|c|}
\hline \multirow{2}{*}{$\begin{array}{l}\text { Drying temperature } \\
\qquad\left({ }^{\circ} \mathrm{C}\right)\end{array}$} & \multicolumn{2}{|c|}{ Chlorophyll $a$} & \multicolumn{2}{|c|}{ Chlorophyll $b$} \\
\hline & WL & PL & WL & PL \\
\hline 20 & $491.8 \pm 4.4 \mathrm{a} * \mathrm{~A} * *$ & $450.8 \pm 6.8 \mathrm{~B}$ & $271.2 \pm 5 \mathrm{aC}$ & $251.4 \pm 6.3 \mathrm{aD}$ \\
\hline 40 & $442.0 \pm 3.0 \mathrm{bA}$ & $375.6 \pm 5.4 \mathrm{bB}$ & $236.8 \pm 6.7 \mathrm{bC}$ & $225.6 \pm 3.8 \mathrm{bD}$ \\
\hline 60 & $314.2 \pm 4.5 \mathrm{cA}$ & $299.6 \pm 6.5 \mathrm{cB}$ & $203.6 \pm 5.1 \mathrm{cC}$ & $186.4 \pm 6.3 \mathrm{cD}$ \\
\hline
\end{tabular}

DT - drying temperature, WL - whole leaves, PL - pulped leaves. The values designated by the different: small letters in the columns and capital letters in the lines; of the table are significantly different $(\alpha=0.05)$.

This change could have come about by a limitation of the oxidative changes of the metabolites taking place because the oxygen concentration was very low during the freezedrying process. Moreover, we observed that a higher drying temperature initiated lower changes in $B I$. These changes were particularly visible during the freeze-drying of WL. The lowest increase in $B I$ was observed for WL freezedried at $60^{\circ} \mathrm{C}$ (average 51.9), whereas the highest values of this index were obtained when WL and PL were lyophilized at $20^{\circ} \mathrm{C}$. These results reveal that at a higher temperature of lyophilization, the colour changes are limited.

Chlorophylls are pigments abundantly found in green vegetables and are strongly related to the colour characteristics. Hence, they are an important quality parameter, reflecting a certain aspect of the final dried product and thus playing a crucial role in the overall consumer acceptability (Korus, 2013). The average contents of chlorophyll $a$ and chlorophyll $b$ in fresh kale leaves were 510.2 and $282.4 \mathrm{mg}$ $100 \mathrm{~g}^{-1} \mathrm{DM}$, respectively. The effect of the freeze-drying temperature and the pulping on the chlorophyll content in kale is presented in Table 5. The freeze-drying engendered a decrease in both chlorophyll $a$ and chlorophyll $b$. This tendency was more noticeable with an increase in the drying temperature. Slightly higher degradation was observed for pulped leaves. These degradations are induced by the oxidation brought about by the contact of the pulped kale with air. An increase in the freeze-drying temperature decreased the contents of both forms of chlorophyll; the highest decrease was observed when the drying temperature was $60^{\circ} \mathrm{C}$ (an average of approximately about 40 and $31 \%$, respectively). The lowest drying temperature $\left(20^{\circ} \mathrm{C}\right)$ caused only a slight decrease in chlorophylls (an average of $8 \%$ for both forms of chlorophyll). In general, when a higher freeze-drying temperature was applied, a higher degradation of chlorophyll $a$ was observed, in comparison to chlorophyll $b$. The chlorophyll $b$ form was more resistant to heat treatment because of the lower susceptibility of this pigment to pheophytin formation (Araújo et al., 2016; Cui et al., 2004). Lefsrud et al. (2008) compared different methods and temperatures of kale drying and they found that the highest stability of carotenoids was obtained for freeze-dried kale and at a drying temperature of $<25^{\circ} \mathrm{C}$. 
Results of $T P C$ and $A A$ in fresh and dried kale are presented on Fig. 2. The highest value of TPC and $A A$ (the lowest values of $\mathrm{EC}_{50}$ ) were obtained for kale leaves before drying (66.3 $\mathrm{mg} \mathrm{GAE} / \mathrm{g} \mathrm{DM}$ and $86.7 \mathrm{mg} \mathrm{DM} \mathrm{ml}^{-1}$, respectively). Freeze-drying caused a slight decrease in both $T P C$ and $A_{A}$. The process temperature had, however, little influence on $T P C$ and $A A$. Slightly lower values of $T P C$ and higher values of $\mathrm{EC}_{50}$ were obtained for kale dried at a higher temperature. Most importantly, the pulping of leaves before freezes-drying had no negative effects on both $T P C$ and $A A$, and similar or even slightly higher values of these parameters were obtained for PL, as compared to WL. Korus (2011) compared the different drying methods of kale drying and found that the higher levels of TPC and $A A$ were obtained for freeze-dried leaves than for the airdried ones. Further, Oliveira et al. (2015) found that the convective drying of kale generated a slight decrease in $T P C$ and a significant decrease in $A A$ (approximately twofold), particularly when the air temperature exceeded $50^{\circ} \mathrm{C}$. In our study, we showed that the freeze-drying temperature (range $20-60^{\circ} \mathrm{C}$ ) has little influence on both $T P C$ and $A A$.

\section{CONCLUSIONS}

1. The freeze-drying kinetics of kale was the best described by the Page model. The model exhibited a very good fit to experimental data, mainly because of the high values of the coefficient of determination, and the lowest values of root mean square error, along with a decrease in the $\chi^{2}$ test.

2. Increasing the freeze-drying temperature from 20 to $60^{\circ} \mathrm{C}$ decreased the drying time by approximately twofold. The pulping of kale also decreased the drying time. However, the effect was most visible for material dried at temperature $20^{\circ} \mathrm{C}$ (a decrease in the drying time of approximately $36 \%$ ).

3. The freeze-drying of kale significantly increased the lightness, delta Chroma and browning index, and had little influence on hue angle. The highest increase in the lightness and delta Chroma was observed for whole pieces freezedried at $20^{\circ} \mathrm{C}$. Increasing the drying temperature slightly decreased the lightness, delta Chroma and total phenolics content. Furthermore, pulping significantly decreased lightness and browning index and slightly decreased hue angle.

4. Freeze-drying caused a slight decrease in both total phenolics content and antioxidant activity, in comparison to samples before drying. The process temperature and the pulping of kale before drying had little influence on total phenolics content and antioxidant activity. Lyophilization decreased both chlorophyll $a$ and chlorophyll $b$. This tendency became noticeable with an increase in the drying temperature.

5. The best quality freeze-dried kale was obtained at temperature $20^{\circ} \mathrm{C}$ and for unpulped leaves.
Conflict of interest: The Authors do not declare conflict of interest.

\section{REFERENCES}

Albornoz K. and Cantwell M.I., 2016. Fresh-cut kale quality and shelf-life in relation to leaf maturity and storage temperature. Acta Horticulturae, 1141, 109-116.

Alibas I., 2009. Microwave, vacuum, and air drying characteristics of collard leaves. Drying Technology, 27, 1266-1273.

Araújo A.C., Oliveira S.M., Ramos I.N., Brandão T.R.S., Monteiro M.J., and Silva C.L.M., 2017. Evaluation of drying and storage conditions on nutritional and sensory properties of dried galega kale (Brassica oleracea L. var. acephala). J. Food Quality, doi:10.1155/2017/9393482.

Araújo A.C., Oliveira S.M., Ramos I.N., Brandão T.R.S., and Silva C.L.M., 2016. Influence of pretreatments on quality parameters and nutritional compounds of dried galega kale (Brassica oleracea L. var. Acephala). Food Bioprocess Technol., 9, 872-881.

Armesto J., Carballo J., and Martínez S., 2015. Physicochemical and phytochemical properties of two phenotypes of galega kale (Brassica oleracea L. var. Acephala cv. Galega). J. Food Biochem., 39, 439-448.

Arslan D. and Özcan M.M., 2008. Evaluation of drying methods with respect to drying kinetics, mineral content and colour characteristics of rosemary leaves. Energy Conversion Manag., 49, 1258-1264.

Ayaz F.A., Glew R.H., Millson M., Huang H.S., Chuang L.T., Sanz C., and Hayirlioglu-Ayaz S., 2006. Nutrient contents of kale (Brassica oleracea L. var. Acephala DC.). Food Chem., 96, 572-579.

Cui Z.-W., Xu S.-Y., and Sun D.-W., 2004. Effect of microwavevacuum drying on the carotenoids retention of carrot slices and chlorophyll retention of Chinese chive leaves. Drying Techn., 22, 563-575.

Darvishi H., Khoshtaghaza M.H., and Minaei S., 2014. Drying kinetics and colour change of lemon slices. Int. Agrophys., 28(1), 1-6.

Demir V., Gunhan T., Yagcioglu A.K., and Degirmencioglu A., 2004. Mathematical modelling and the determination of some quality parameters of air-dried bay leaves. Biosystems Eng., 88(3), 325-335.

Guiboileau A., Sormani R., Meyer C., and MasclauxDaubresse C., 2010. Senescence and death of plant organs: Nutrient recycling and developmental regulation. Comptes Rendus - Biologies, 333, 382-391.

Henderson S.M. and Pabis S., 1961. Grain drying theory. II. Temperature effects on drying coefficients. J. Agric.Eng. Res., 6, 169-174.

Huang M., Zhao W., Wang Q., Zhang M., and Zhu Q., 2015. Prediction of moisture content uniformity using hyperspectral imaging technology during the drying of maize kernel. Int. Agrophys., 29, 39-46.

Kirmaci V., Usta H., and Menlik T., 2008. An experimental study on freeze-drying behavior of strawberries. Drying Technol., 26, 1570-1576.

Korus A., 2011. Effect of preliminary processing, method of drying and storage temperature on the level of antioxidants in kale (Brassica oleracea L. var. Acephala) leaves. LWT Food Science Technol., 44, 1711-1716. 
Korus A., 2012. Amino acid retention and protein quality in dried kale (Brassica oleracea L. var. Acephala). J. Food Proc. Preservation, 38, 676-683.

Korus A., 2013. Effect of preliminary and technological treatments on the content of chlorophylls and carotenoids in kale (Brassica oleracea L. var. Acephala). J. Food Proc. Preservation, 37, 335-344.

Lefsrud M., Kopsell D., Sams C., Wills J., and Both A.J., 2008. Dry matter content and stability of carotenoids in kale and spinach during drying. HortSci., 43, 1731-1736.

Mansur A.R. and Oh D., 2015. Combined effects of thermosonication and slightly acidic electrolyzed water on the microbial quality and shelf life extension of fresh-cut kale during refrigeration storage. Food Microbiol., 51, 154-162.

Marques L.G. and Freire J.T., 2005. Analysis of freeze-drying of tropical fruits. Drying Technol., 23, 2169-2184.

Murador D.C., Mercadante A.Z., and De Rosso V.V., 2016. Cooking techniques improve the levels of bioactive compounds and antioxidant activity in kale and red cabbage. Food Chem., 196, 1101-1107.

Mwithiga G. and Olwal J.O., 2005. The drying kinetics of kale (Brassica oleracea) in a convective hot air dryer. J. Food Eng., 71(4), 373-378.

Nakagawa K. and Ochiai T., 2015. A mathematical model of multi-dimensional freeze-drying for food products. J. Food Eng., 161, 55-67.

Oliveira S.M., Ramos I.N., Brandão T.R., and Silva C.L., 2015. Effect of air-drying temperature on the quality and bioactive characteristics of dried kale (Brassica oleracea L. var. Acephala). J. Food Proc. Preservation, doi:10.1111/ jfpp. 12498.

Ragaert P., Devlieghere F., and Debevere J., 2007. Role of microbiological and physiological spoilage mechanisms during storage of minimally processed vegetables. Postharvest Biol. Technol., 44, 185-194.

Re R., Pellegrini N., Proteggente A., Pannala A., Yang M., and Rice-Evans C., 1999. Antioxidant activity applying an improved ABTS radical cation decolorization assay. Free Radical Biology Medicine, 26, 1231-1237.

Rudy S., Dziki D., Krzykowski A., Gawlik-Dziki U., Polak R., Rózyło R., and Kulig R., 2015. Influence of pre-treatments and freeze-drying temperature on the process kinetics and selected physico-chemical properties of cranberries (Vaccinium macrocarpon ait.). LWT - Food Sci. Technol., 63, 497-503.
Sarimeseli A., 2011. Microwave drying characteristics of coriander (Coriandrum sativum L.) leaves. Energy Conversion Manag., 52(2), 1449-1453.

Serratosa M.P., Marquez A., Lopez-Toledano A., Medina M., and Merida J., 2011. Differences in browning index and CIELAB coordinates of the two grape drying processes, traditional sun-drying and chamber-drying and during the ageing of Pedro Ximenez sweet wine. J. Life Sci., 5, 974-980.

Shofian N.M., Hamid A.A., Osman A., Saari N., Anwar F., Dek M.S.P., and Muhammad Hairuddin M.R., 2011. Effect of freeze-drying on the antioxidant compounds and antioxidant activity of selected tropical fruits. Int. J. Molecular Sci., 12, 4678-4692.

Singleton V.L. and Rossi A., 1965. Colorimetry of total phenolics with phosphomolybdic-phosphotungstics acid reagents. American J. Enology Viticulture, 16, 144-158.

Sogi D.A., Siddiq M., Greiby I., and Dolan K.D., 2013. Total phenolics, antioxidant activity, and functional properties of 'Tommy Atkins' mango peel and kernel as affected by drying methods. Food Chemistry, 141, 2649-2655.

Soysal Y., Öztekin S., and Eren Ö., 2006. Microwave drying of parsley: modeling, kinetics, and energy aspects. Biosys. Eng., 93, 403-413.

Steindal A.L.H., Rdven R., Hansen E., and Mlmann J., 2014. Effects of photoperiod, growth temperature and cold acclimatisation on glucosinolates, sugars and fatty acids in kale. Food Chemistry, 174, 44-51.

Traka M. and Mithen R., 2009. Glucosinolates, isothiocyanates and human health. Phytochemistry Reviews, 8, 269-282.

Van Duyn M.A.S. and Pivonka E., 2000. Overview of the health benefits of fruit and vegetable consumption for the dietetics professional: Selected literature. J. American Dietetic Association, 100, 1511-1521.

Verkerk R., Schreiner M., Krumbein A., Ciska E., Holst B., Rowland I., De Schrijver R., Hansen M., Gerhäuser C., Mithen R., and Dekker M., 2009. Glucosinolates in Brassica vegetables: The influence of the food supply chain on intake, bioavailability and human health. Molecular Nutrition Food Res., 53, S219-S265.

Wang C.Y. and Singh R.P., 1978. Use of variable equilibrium moisture content in modeling rice drying. Trans. ASAE, 11, 668-672. 